\title{
La articulación del fracaso en dos autores latinoamericanos: Arturo, la estrella más brillante de Reinaldo Arenas y Estrella distante de Roberto Bolaño
}

\author{
The discurse of failure on two Latin American authors: \\ Arturo, la estrella más brillante by Reinaldo Arenas \\ and Estrella distante by Roberto Bolaño
}

\section{Mauricio Arenas Oyarce}

Pontificia Universidad Católica de Valparaíso. Valparaíso, Chile mauriarenas@gmail.com

\section{RESUMEN}

Roberto Bolaño y Reinaldo Arenas lograron plasmar en sus novelas -Estrella distante y Arturo, la estrella más brillante, respectivamente- la sensación que produce en el sujeto contemporáneo el fracaso, producto de cambios político-sociales que movilizan en sus personajes -ambos Arturos, alter egos de sus autores- la sensación de la pérdida del ser, categoría ontológica comprendida aquí como gesto de autodestrucción. Todo esto ambientado en espacios signados por la decadencia, el deterioro y la destrucción. Ambos proyectos narrativos se comunican, desde la óptica de la literatura comparada, revelando en Bolaño la puesta en escena del 'mal' como eje central y transversal que se superpone a un mezquino y maleable concepto de verdad y en Arenas como una visión apocalíptica de la revolución que en principio apoyó, y por lo tanto integró, pero que finalmente lo termina excluyendo.

Palabras clave: Pérdida del ser, literatura comparada, fracaso, dictadura, revolución cubana.

\section{ABSTRACT}

The authors pictured on their novels -Estrella distante and Arturo, la estrella más 
brillante - the feeling of failure of a modern man. The feelings are produced by political and social changes that drive the protagonists -both protagonists with alter egos of each writer- the feeling of lost self, ontological category, here understood as a selfdestruction behavior. The setting is characterized by decadence places, degradation and destruction. Both narrative projects express themselves from the point of view of comparative literature, shown by Bolaño the staging of 'evil' as transverse axis, that overlaps a mean and malleable concept of truth and Arenas as an apocalyptic vision of the revolution which was originally supported by he, butt ends up excluding it.

Keywords: Loss of self-identity, comparative literature, failure, dictatorship, Cuban revolution.

Recibido: 05.08.2013. Aceptado: 08.10.2013.

T a literatura latinoamericana se ha caracterizado, desde sus primeras ex$\checkmark$ presiones a partir del siglo XVI, por representar un universo fracturado por las tensiones que este espacio ha padecido, en un ejercicio de revelación y rebelión que denuncia una historia inabarcada por los otros discursos que cohabitan las sociedades latinoamericanas. En este contexto, surgen diversas visiones que reconstruyen las relaciones entre los sujetos y los espacios por ellos habitados en un contradictorio movimiento doble de aceptación/pertenencia y rechazo/extrañeza. Este fenómeno se evidencia, en las literaturas propias del continente, de forma diversa aunque presentando de alguna $\mathrm{u}$ otra manera hilos conductores que permiten agrupaciones superficiales aptas para el análisis, pero principalmente presentan diferencias profundas que terminan por develar las características propias y únicas de cada individuo y lugar, evidenciando un locus de enunciación que, a pesar de las semejanzas históricas, realza sus diferencias identitarias, políticas, culturales, sociales y regionales, entre otras.

En este contexto, llama la atención un aspecto que se reitera en una serie de narrativas producidas o ambientadas en los períodos dictatoriales característicos de la segunda mitad del siglo XX. Un grupo diverso de novelistas latinoamericanos ha comulgado con una narrativa de la que emana la representación del fracaso en las múltiples formas que éste puede asumir, a través de la nostalgia, la pérdida del $\operatorname{ser}^{1}$ o el sentimiento de ausencia. Estos motivos se reiteran en distintas novelas, adquiriendo matices interesantes y

${ }^{1}$ Este concepto funcionará como eje central del análisis de las novelas de Roberto Bolaño y Reinaldo Arenas mencionadas en el título del artículo. 
transformaciones sustanciales que evidencian una evolución en la temática, desde la sensación de fracaso motivada, principalmente, por la caída de los grandes metarrelatos, en donde el sujeto comprende los fenómenos bajo una óptica binaria que divide a los actores en dos grupos perfectamente delimitados, oprimidos y opresores -buenos y malos- (en esta categoría cabría incluir la novela de Arenas Arturo, la estrella más brillante), hasta una narrativa más compleja que difumina los límites antes establecidos para los sujetos y sus roles sociales, disolviendo las lógicas binarias y relativizando los discursos que se atribuyen los criterios de verdad y legitimidad (afín con el desarrollo de la narrativa de Roberto Bolaño). Bajo la óptica del comparatismo, esta especie de palingénesis que revela las diferencias temáticas de las narrativas en cuestión, evidencia una evolución de la percepción del fracaso -metamorfosis, diría Trousson ${ }^{2}-$ motivada por contextos, fenómenos y épocas diversas, pero relacionadas bajo un campo temático ${ }^{3}$ común: la pérdida del ser.

\section{LA PÉRDIDA: ¿POR QUÉ LLORA PSAMÉNITO, REY DE EGIPTO?}

\section{La enigmática historia de Heródoto, que recupera Benjamin en El narrador y antes Montaigne en sus Ensayos, despliega un sinfín de posibilidades que}

\footnotetext{
${ }^{2}$ Según Anna Trocchi, uno de los aspectos más relevantes de la tematología, para Trousson, radica en la capacidad de interpretar las variaciones temáticas en la literatura, según los distintos fenómenos sociales y epocales bajo los cuales emerja: "según Trousson, la finalidad de un estudio tematológico es la de interpretar las variaciones y las metamorfosis de un tema literario a través del tiempo, a la luz de sus relaciones con las orientaciones contextuales históricas, ideológicas e intelectuales, y evidenciar así la <adaptación de los elementos constitutivos del tema a las transformaciones de las ideas y las costumbres>" (2002.: 136).

${ }^{3}$ Siguiendo a Dolezel; "Cada tema es miembro de un mini-sitema de temas relacionados, un campo temático, y su estructura es determinada principalmente por las oposiciones existentes dentro de ese campo" (1999: 264).

${ }^{4}$ La enigmática historia de Psaménito es utilizada por Benjamín en El narrador, para reflexionar en torno a la capacidad de reinvención constante que la narración le permite a la literatura. A continuación reproducimos la síntesis que Benjamin realiza de la historia de Heródoto: "Cuando Psaménito, rey de los egipcios fue derrotado y capturado por el rey persa Cambises, este último se propuso humillar al prisionero. Dio orden de situar a Psaménito en la calle por donde debía pasar el cortejo triunfal de los persas. Dispuso además que el prisionero viera a su hija pasar en calidad de criada que llevaba el cántaro a la fuente. Mientras todos los egipcios se dolían y lamentaban ante el espectáculo. Psaménito permanecía solo, callado e inmutable, los ojos clavados en el suelo; y permaneció igualmente inmutable al ver pasar a su hijo, momento después, que era conducido en el desfile para su ejecución. Pero cuando luego reconoció en las filas de los prisioneros a uno de sus criados, un hombre anciano y empobrecido, se golpeó la cabeza con los puños y mostró todos los signos de la más profunda aflicción" (2008: 69).
} 
intentan dar explicación al llanto del Rey ante la desdicha de un sirviente (y no la de sus hijos) $)^{5}$. Pero, existen elementos que los estudiosos mencionados, insólitamente, no escatimaron y que funcionan como metáfora introductoria a nuestro análisis. Los martirios que intenta provocarle Cambises buscan incitar dolor al rey de los egipcios. A pesar de la angustiante escena, Psaménito no llora al ver pasar a sus hijos, pues a ellos no los pierde, el lazo que une las relaciones filiales es inquebrantable por los mortales. Incluso después de la muerte, sus hijos serán sus hijos. Pero, la relación que une al rey con su servidumbre se basa en un lazo artificial (o social), creado por el propio ser humano -quien, por ende, puede destruirlo-. Su servidumbre es lo único que Cambises realmente puede arrebatarle al rey. Recordemos la importancia que adquiere, según la cosmovisión de la cultura egipcia, el rito mortuorio en el cual el emperador debe ser sepultado con sus riquezas y bienes más preciados (en ocasiones incluso con sus sirvientes más cercanos) para que lo acompañen en el viaje a la otra vida y así poder gozar de las mismas comodidades de las que se rodeó en ésta. El desconsuelo surge ante la trágica revelación de la pérdida irreparable, de la nostalgia por aquel pasado reciente que probablemente nunca volverá. En la vida después de la vida, sus hijos serán sus hijos, pero la servidumbre (en ellos el reino, su pueblo) ya no le pertenecerá.

Esta historia, que bien podría servirnos como mito literario, si ampliamos el concepto, despojándolo del componente estrictamente religioso, funciona como gozne articulatorio que conecta el tema analizado con la historia del hombre 6 . En este sentido, la tragedia de Psaménito representa la génesis de un tema que se fue transformando en un elemento representativo de la literatura, en especial desde la fractura que experimenta el sujeto contemporáneo. La pérdida, la ausencia, la nostalgia, todos sentimientos de un universo semántico cuyas relaciones son interminables y se extienden multidireccionalmente a otros horizontes que van relacionando la experiencia de los sujetos con los fenómenos exteriores que determinan sus estados. Bajo esta óptica resulta interesante seguir la huella de dos literaturas que, preliminarmente, plasmarían de alguna forma -tal vez muy semejante o en suma diferente- estos estados. La narrativa latinoamericana y del Caribe

${ }^{5}$ En las explicaciones que cita y propone Benjamin, prima la idea de la contención del dolor que afloraría ante la visión del sirviente como consecuencia de un proceso de acumulación de la aflicción. En este sentido, el sirviente es, simplemente, la gota que desborda el vaso.

${ }^{6}$ Eliade, en relación a los mitos, los define como aquellos relatos que configuran la génesis del hombre: "Los mitos cuentan no solo el origen del mundo de los animales, de las plantas y del hombre, sino también de todos aquellos sucesos primordiales por los que el hombre ha llegado a ser lo que es hoy, es decir mortal, sexuado, organizado en sociedad" (en Gnisci, 2002: 145). 
ha evidenciado puntos de contacto que permiten asimilarla, aunque con objeciones, a un sistema literario que, evitando homologaciones procustianas, presenta una serie de elementos que se reiteran en distintas épocas y autores a lo largo de la región. Una marca distintiva de la novelística contemporánea ha sido el sentimiento de pérdida que arrojan, como resultado de transformaciones político-sociales, las creaciones artísticas de una gran mayoría de escritores. ¿Qué hay, entonces, tras esa nostalgia por la pérdida, tras la ausencia que se reitera en escritores distintos, reinventando universos diferentes y acudiendo a referentes diversos? Las asociaciones son múltiples, al igual que las diferencias, pero los puntos de conexión que dan cohesión a este estudio apuntan, principalmente, a la configuración de espacios que remiten a referentes extratextuales que han padecido cambios (de diversa índole y motivados, valga decirlo, por corrientes ideológicas opuestas) cuya materialización dista radicalmente del discurso oficial que intenta legitimar$\operatorname{los}^{7}$.

En apariencia, Estrella distante del chileno Roberto Bolaño y Arturo, la estrella más brillante del cubano Reinaldo Arenas no tendrían más en común que sus títulos (premisa que ningún conocedor del trabajo de Bolaño daría por $\operatorname{cierta}^{8}$ ). La primera de ellas, escrita en 1996, recrea el tiempo de la dictadura militar chilena y las macabras acciones de arte de un oficial de la Fuerza Aérea de Chile (FACH), Carlos Wieder, todo esto narrado a través de la óptica de un alter ego del autor, Arturo B. Por su parte, la obra del cubano, escrita más de diez años antes (1984) recrea el ambiente posrevolución de la Cuba comunista en una cárcel para homosexuales a través de la historia de Arturo ('coincidentemente' otro Arturo), un joven intelectual de la época. Ambas narraciones atrapan con recursos enigmáticos que van configurando universos interesantes en los que poco a poco se va urdiendo una trama argumental que, llegada a sus últimas líneas, abre las posibilidades interpretativas al lector.

\footnotetext{
7 Se impondrá en ciertos espacios determinados por la censura, una discursividad autoritaria que en lo superficial apelará constantemente a valores nacionalistas y antiliberales, pero cuyo trasfondo pretende, en términos foucaultianos, prohibir, separar o rechazar toda forma discursiva que contravenga la oficialidad. En palabras de Michel Foucault, "el discurso no es simplemente aquello que traduce las luchas o los sistemas de dominación, sino aquello por lo que, y por medio de lo cual se lucha" (Foucault, 1996: 15).

${ }^{8}$ Basta revisar el capítulo 23 de su novela Detectives salvajes titulado: Felipe Müller, bar Céntrico, calle Tallers, Barcelona, septiembre de 1995, en el cual, por medio de sus personajes, Bolaño rescata las biografías de dos escritores latinoamericanos. El guiño a Reinaldo Arenas es evidente. Ver Bolaño, 1998: 496-500.
} 


\section{ESTRELLA DISTANTE: LA PÉRDIDA COMO NAUFRAGIO}

Ortega y Gasset, desde la filosofía, plantea la relación del sujeto y su contexto en la imagen del náufrago: "Vivir es encontrarse náufrago entre las cosas. No hay más remedio que agarrarse a ellas. Pero ellas son fluidas, indecisas, fortuitas. De aquí que nuestra relación con las cosas sea constitutivamente inseguridad" (1983), apelando principalmente al sentimiento de desamparo que caracterizaría al ser. En este sentido, la metáfora manifiesta la condición moderna del individuo en relación a una conciencia fracturada.

Bolaño recrea magistralmente la distopía moderna que la sociedad chilena padece en la época. La narrativa, simulando una novela policial, escudriña en un caso de tintes policíacos, en donde el narrador-protagonista y el lector se transforman en los investigadores que siguen las pistas necesarias para reconstruir el itinerario de Wieder. En este recorrido, el lector se ve instado a seguir un camino distinto, más oculto, solapado tras el disfraz del drama policial, cuya tarea apunta a develar guiños, rastros, huellas, intertextualidades que el autor va entregando para configurar una panorámica crítica de lo que fue el escenario cultural y social de la época. Las peripecias en avión realizadas por Wieder, su escritura en los cielos, remiten oblicuamente a una serie de intervenciones artísticas realizadas por grupos de creadores que se revelan contra el discurso oficial en la década de los $80^{9}$. Este guiño intertextual a la vanguardia artística reconfigura las coordenadas del lector. Ya no estamos frente a una novela que utilice como referente único los crímenes cometidos por la dictadura militar. Bolaño amplía su crítica a otros actores que intervienen en la época. La poética del chileno puede ser entendida como la puesta en evidencia del mal -siguiendo a Daniuska González (2003) - en todas sus formas, independiente de la ideología bajo la cual se exprese. Presente en todos los rincones de nuestras sociedades, a pesar de aquellas acciones realizadas por aparatos institucionales que se atribuyen la tarea de erradicarlo (el mal disfrazado de bien). "Al igual que la condición humana individual, la sociedad [...] comparte un lado de sombras y oscuridad, con otro resplandeciente, de luz y vigorosa claridad" (González, 2003, 32). Bajo estos supuestos, el autor se dedica a cuestionar, en definitiva, cualquier tipo de orden dictatorial que pretenda coartar la libertad de las personas (gesto que seguramente Bolaño reconoció en Arenas y explicita en

${ }^{9}$ El doce de julio de 1981, el grupo CADA lanza desde aviones que sobrevuelan la ciudad de Santiago, cuatrocientos mil volantes con la leyenda: CADA HOMBRE QUE TRABAJA POR LA AMPLIACIÓN, AUNQUE SEA MENTAL, DE SUS ESPACIOS DE VIDA ES UN ARTISTA. Esta acción de arte tuvo por nombre "Ay Sudamérica". Ver: Neustadt, 2001. 
la cita evidente entre los títulos de las obras y el nombre del protagonista). El mal acechará desde todas partes, por sobre las ideologías o colores políticos, el mal logra camuflarse, travestirse de bien para imponerse. Todo pasará, entonces, por una cuestión de perspectiva. Es aquí cuando surge la imagen del naufragio, en el sentido de la pérdida, de la destrucción del proyecto. En las primeras líneas de la novela, Arturo reconoce el inminente hundimiento del proyecto nacional: "Por aquellos días, mientras se hundían los últimos botes salvavidas de la Unidad Popular" (Bolaño, 1996: 34). Naufragio en el que nadie resulta ileso ('ni derechas ni izquierdas'), todo el mundo está a la deriva. La metáfora se plasma en forma más que explícita en el relato de un sueño del protagonista:

Soñé que iba en un gran barco de madera, un galeón tal vez, y que atravesábamos el Gran Océano. Yo estaba en una fiesta en la cubierta de popa y escribía un poema o tal vez la página de un diario mientras miraba el mar. Entonces alguien, un viejo, se ponía a gritar ¡tornado! ¡tornado!, pero no a bordo del galeón sino a bordo de un yate o de pie en una escollera [...] En ese instante el galeón comenzaba a hundirse y todos los sobrevivientes nos convertíamos en náufragos. En el mar, flotando agarrado a un tonel de aguardiente, veía a Carlos Wieder. Yo flotaba agarrado a un palo de madera podrida. Comprendía en ese momento, mientras las olas nos alejaban, que Wieder y yo habíamos viajado en el mismo barco, sólo que él había contribuido a hundirlo y yo había hecho poco o nada para evitarlo (Bolaño, 1996: 130).

Un naufragio de todos. Las últimas palabras de la cita son reveladoras en tanto dan indicios de la verdadera crítica que solapa la obra de Bolaño: "y yo había hecho poco o nada para evitarlo". Ese yo es el opuesto al Otro que es Wieder y que identificamos, ya a estas alturas con la ultraderecha o las ideologías conservadoras pro gobierno militar. Ergo, el yo se extiende hacia aquellos sujetos que se declaran de izquierda, opositores al régimen, la Escena de Avanzada, por ejemplo, que por aquel entonces realizaba acciones de arte que pretendían desarticular los discursos implantados por la represión, en un gesto a un tiempo artístico y político ${ }^{10}$. Según Nelly

10 "La escena de avanzada o nueva escena designa un grupo de prácticas que se caracterizó -dentro del campo anti-dictatorial- por su experimentalismo neovanguardista. Esas prácticas se generaron -después de 1977- desde la plástica (Eugenio Dittborn, Carlos Leppe, Juan Dávila, Carlos Altamirano, el grupo CADA, Lotty Rosenfeld, Catalina Parra, Alfredo Jaar, etc.) y desde la literatura (Raúl Zurita, Diamela Eltit, Diego Maqueira, Juan Luis Martínez, Gonzalo Muñoz, 
Richard, el carácter más polémico de estos artistas era el "radicalismo crítico de sus experimentaciones de lenguajes dirigidas vehementemente contra el sistema-arte" (Richard, 2000: 39-40). Para Bolaño, estos gestos son insuficientes para atribuirse los derechos de resistencias, contrarrevolución o simplemente para librarse de la culpa que ameritan los crímenes cometidos en la época (esta revelación es la misma que Arenas plasmará a través de su personaje en la novela estudiada). Por esta vertiente ingresamos a una de las aristas más interesante de la obra del chileno, el cuestionamiento al discurso que impone la modernidad. En una de sus entrevistas, el autor reconoce parodiar a cualquier sector o ideología que se atribuya el derecho de hablar en nombre de la verdad. En sus palabras:

el mundo de la ultraderecha es un mundo desmesurado y es interesante de por sí. Lo que pasa es que yo cojo el mundo de la ultraderecha, pero muchas veces, en realidad, de lo que estoy hablando es de la izquierda. Cojo la imagen más fácil de ser caricaturizada para hablar de otra cosa. Cuando hablo de los escritores nazis de América, en realidad estoy hablando del mundo a veces heroico, y muchas más veces canalla, de la literatura en general (en Dés, 1998).

En esta parodia seria o transposición ${ }^{11}$, Bolaño rearticula las coordenadas propias de la novela policial para mostrarnos que el delito -el mal infringido- no le es propio solamente a un sector de los individuos sociales. La novela policial clásica consiste en dilucidar una verdad que, al final de sus páginas, es incuestionable. Una verdad instaurada por la conciencia moderna, como única y verificable (aquel 'saber' del que nos habla Sepúlveda (2003: 111). El gesto del autor pretende evidenciar que la 'verdad', el 'delito', el 'mal', lo serán, dependiendo de la perspectiva que prime en el

Soledad Fariña, etc.) replanteando una reconceptualización crítica de los lenguajes, técnicas y géneros, del arte y de la literatura heredados de la tradición artística y literaria" (Richard, 2000: 55). Por su parte, Pablo Oyarzún define los principales objetivos de la escena de avanzada, por una parte como "la exigencia de evidenciar en la obra lucidez analítica acerca de la nacionalidad social e ideológica de su propio ejercicio" y por otra "una tensa lógica de confrontación entre su status (y su voluntad) de marginalidad y las distintas instancias institucionalizadas" (en Richard, 2000: 40).

${ }^{11}$ Genette clasifica las relaciones intertextuales en: "Parodia, como el desvío de un texto con una transformación mínima (...); travestismo como la transformación estilística con función degradante (...); ridiculización (y ya no parodia) como el pastiche satírico, donde A la manera de... son ejemplos canónicos, y del cual el pastiche heroico-cómico no es sino una variedad; y llamar simplemente pastiche a la imitación de un estilo sin función satírica”. Finalmente, y para evitar posibles vicios o errores a los que podrían inducir términos tan ampliamente utilizados, propone para las transformaciones serias el término transposición (Genette, 1982). 
discurso. El proyecto moderno se legitima por medio de la reproductibilidad explicativa y racional del mundo, "la noción de que todo obedece a una causa, y que, por tanto, todo es explicable, pertenece al discurso de la modernidad, ya que este, concebía el mundo como un objeto manipulable sobre el cual se opinaba de manera exacta, cuantificable y disyuntivamente" (Sepúlveda, 2003: 106). Bolaño nos revela un espacio y una época oscura, signada por la pérdida, desmantelándonos al mismo tiempo aquel discurso que se pretende instalar como rector. Esta cuestión forma parte esencial del proyecto de Bolaño; el paratexto de Monsieur Pain (escrita en 1981 ó 1982) es Revelación mesmérica de Edgar Allan Poe, en donde podemos encontrar, en pocas líneas, un fragmento enigmático que nos remite, incipientemente, a lo que pronto desarrollará Bolaño en Estrella distante. La parcialidad que el lenguaje (y la razón moderna) conllevan, otorga una percepción limitada de la realidad. En palabras de los personajes de Poe: "las estrellas, en tanto, mediante lo que consideramos su materialidad, escapan al sentido angélico, al igual que la materia no-particular, mediante lo que consideramos su inmaterialidad, elude lo orgánico" (en Espinosa, 2003: 105). El fragmento revela, utilizando como ejemplo precisamente a las estrellas (nada es coincidencia en Bolaño), cómo la explicación del pensamiento sólo logra aprehender parte de la totalidad de los fenómenos. La elección de un aspecto irremediablemente negará a un opuesto que también es constituyente de la realidad. Estas deducciones se amplían en la narrativa de Bolaño y se sitúan en las acciones de las distintas ideologías y de los distintos sujetos que en la época intentaban, según la visión de cada cual, diferenciarse entre los buenos y los malos. "Aquí todos son responsables", se desprende del sueño del protagonista, porque la 'verdad', que la modernidad instaura bajo estrategias de legitimación, no es tal. Ante una revelación tan cruda, la existencia del hombre queda condicionada a una distopía que supera las representaciones de una sociedad totalitaria y opresiva y apunta más bien a la inexistencia de proyectos redentores, al 'naufragio' a la deriva de toda ideología liberadora. En palabras de Patricia Espinosa, existiría una "no satisfacción de la nostalgia de unidad o denegación a la existencia idealista de verdad. Bolaño nos demuestra que no hay origen, sino trazas" (Espinosa, 2003: 20). En esta fractura, el autor nos revela un sujeto nostálgico, que no logra idealizar el pasado pero tampoco puede proyectarse en un futuro.

El cuestionamiento de la verdad asoma incluso desde los aspectos más propios del universo discursivo. Las incertidumbres del narrador superan ampliamente la parcela de certezas que pretende poseer. Basta sólo una lectura a las primeras páginas de la novela para comprobar que la intención 
discursiva apunta a difuminar la 'verdad' en el espacio del rumor, la incertidumbre o el olvido. Arturo, cual narrador del Quijote, no entrega especificaciones de los personajes o de los acontecimientos:

La primera vez que vi a Carlos Wieder fue en 1971 o tal vez en 1972, cuando Salvador Allende era presidente de Chile.

Entonces se hacía llamar Alberto Ruiz-Tagle y a veces iba al taller de poesía de Juan Stein, en Concepción, la llamada capital del Sur. No puedo decir que lo conociera bien. Lo veía una vez a la semana, dos veces, cuando iba al taller (Bolaño, 1996: 6).

No hay certezas en la obra de Bolaño. En términos discursivos, todo el tratamiento de la obra apela a la insoportable sensación de la ignorancia. $\mathrm{Al}$ conocimiento parcelado de la verdad. Esa verdad a medias, que se nos presenta como única pero que realmente comprende una cara oculta que no logramos ver, un doble opuesto que se nos niega.

\section{ARTURO, LA ESTRELLA MÁS BRILLANTE: LA PÉRDIDA COMO ALEGORÍA}

Arturo, aquel joven homosexual e intelectual cubano, alter ego de Reinaldo Arenas, ve pasar sus mejores años en la cárcel que la revolución ha dispuesto como reformatorio para los homosexuales. Su tránsito configura una dicotomía que representa un acercarse por medio de la construcción -de aquella alegoría última- a la destrucción final que representa su 'muerte' y la desaparición de este universo alegórico desde donde Arturo intentaba crear un escape, un mundo paralelo, en el cual refugiarse para evitar la cotidianidad, la banalidad y el encierro que debía soportar. La narración de la novela es primordial para la consecución temática de la obra. El juego incesante de un narrador extradiegético que se confunde con el protagonista, nos somete a una fluidez interminable de frases que no concluyen nunca con puntos aparte, sino hasta el final (la destrucción). Este viaje configura, como dirá Rocío Gordon, un "texto torrencial" (2008: 203) que no deja respiro al lector. La coincidencia de los niveles de la historia con los recursos narrativos recrea un mundo que vaticina, desde sus primeras líneas, su destrucción hacia el final:

El texto total y la 'destrucción' de Arturo se entregan como un torrente desbordante de lenguaje, el que impone en la lectura, una literal conten- 
ción de aliento para adecuarse a un ritmo que se prolonga sin interrupción desde la primera línea del relato hasta la última, desde la construcción (escritura y prolongación de la misma) hasta la destrucción por parte de $\mathrm{Ar}-$ turo, de su obra (...) dicha destrucción coincide -como es esperable- con el acabamiento del texto. El temple homogéneo de exaltación contribuye a este efecto de escritura-lectura ininterrumpidas, que sólo se agota en el último lexema; la intensificación de la función poética (...) suscita un efecto lírico (Solotorevsky, 1993, en Gordon: 2008: 203).

La culminación de la novela en su doble función, como destrucción del protagonista, nos propone la pérdida, incluso desde aquel universo más recóndito construido por el sujeto para salvaguardar su individualidad, aquel espacio del ser al que nadie puede llegar. La persecución final que padece Arturo, por parte de los militares, se convierte, en el momento del encuentro, en un enfrentamiento con su propio pasado, la alegoría que hasta entonces sólo abarcaba la conciencia del protagonista (a través de aquella narración que por instantes sugería corriente de la conciencia) se desplaza al espacio exterior de aquella ciudad imaginada; el militar se confunde con su madre, la 'Vieja Rosa', una madre-estado (Bertot) que simboliza la opresión, como el opuesto dicotómico que cruza la narrativa de Arenas. Esa opresión (la madre, los militares, el régimen) posiciona al protagonista en un estado de 'no ser' que volverá a ser sólo si recupera su libertad. Este estado se proyecta en un espacio poco definido por descripciones, en donde la narración desdibuja un ambiente rutinario (a través de las constantes repeticiones) en donde la destrucción y la pérdida también se ven reflejados a través del detrimento de la ciudad:

Las largas madrugadas por los lugares más insólitos de una ciudad hacia las ruinas llegaron; sí, aún había cabarets, cafeterías, algunas fiestas, hasta hubo un carnaval, pero Arturo notaba que casi todos hablaban en pasado y quizás, lo que más le sorprendía (y hasta le fascinaba) dentro de aquel torbellino de aventuras inconclusas, de conversaciones, de encuentros y relaciones inconclusas, era el ver la rapidez con que todo, hasta las mismas calles, hasta los mismos rostros, hasta el tiempo se iba deteriorando, cuarteando, rompiendo, erosionando día tras día y cada vez más, una semana era un cine cerrado, otra, otro producto racionado, otra, un establecimiento clausurado, en un mismo día, todos los árboles de la calle talados sin explicaciones, sin contar con nadie, y la claridad que descendía a la vez que faltaba el agua (Arenas, 1984: 24-25). 
El deterioro de los espacios se proyecta en el deterioro de los sujetos. La sensación de destrucción se prolonga en una agonía perpetua: "algo le decía que todo se estaba pudriendo y también tu vida, y también tu juventud y también todos, todo" (Arenas, 1984: 24-26). El llanto aflora, finalmente ante esta visión. El sujeto se derrumba a destiempo, en la revelación tardía de su nefasto destino -cual Psaménito frente a la verdadera pérdida-:

Antes había tenido ya la visión, por lo demás exacta, de que si el mundo en general era terrible, para él era una prisión estricta y asfixiante que se reducía cada día, una descomunal estafa, un terror incesante, pero no había llorado, y era ahora [...] cuando de súbito comenzaron a brotarle las lágrimas [...] La música y las lágrimas fluyendo, era ahora, era ahora también cuando tomaba conciencia de todas sus desgracias, era ahora cuando veía el cuerpo achicharrado, la casa irrecuperable, espaciándose en forma de remolino, la gran torre y también la paz, era ahora cuando palpaba las dimensiones de una soledad fija (Arenas, 1984: 29-30).

La liberación no llega porque ésta sólo puede conseguirse en la sustitución de otro orden de cosas, de otra realidad palpable y tangible. La literatura tradicional no es útil en este proyecto escritural, por eso el recurso escogido por Arenas es la alegoría. El autor no pretende crear un mundo parecido al real en su obra, este gesto es para él inútil, sólo le queda reproducir alegóricamente una ciudad cuyos elementos le aseguren una cierta felicidad.

Solo con la creación de otro presente se puede eliminar el presente presente, no con relatos, no con recuentos, no con análisis minuciosos o brillantes de lo que ha sucedido y sucede, estos, en fin, no hacen más que afianzar, situar, justificar, evidenciar, darle más realidad a la realidad padecida, no son más que variaciones del mismo terror, y toda variación engrandece el objeto que la origina, la Historia no se ocupa de gemidos, sino de números, de cifras, de cosas palpables, de hechos, de alardes monumentales, y no suele interesarse por los que redactan sino por los que transforman, borran o destruyen, la primera plana no es para el esclavo ni el vencido; a la imagen que se padece, hay que anteponerle, real, la imagen que se desea, no como imagen, sino como algo verdadero que se pueda disfrutar (Arenas, 1984: 53).

Tras una crítica voraz a la Historia, surge el escritor contrarrevolucionario, llamando, insinuando cambiar la realidad, aquella que es imposible 
cambiar, según Arenas, desde la literatura. Su impotencia es evidente. No tiene, en esta prisión asfixiante que lo consume hasta la destrucción, formas de liberación. Surge, entonces, la alegoría, única salida que desde la concepción benjaminiana atrapa la temporalidad del momento en su más evidente decadencia. El gesto de Arenas apunta a recrear en aquella ciudad alegórica que hiperconstruye durante el desarrollo de la novela, una historia destrozada por los acontecimientos, un tiempo idílico que ya no está y que culmina inevitablemente (o culminará) en la destrucción. Lucía Oliván, leyendo a Benjamin, definirá la alegoría como "representación de una concepción de Historia decadente y negativa en la cual no existe la redención y todo tiende a la destrucción" (2004). El recurso alegórico intenta recuperar o retener, en esa temporalidad, aquella utopía que la revolución aplastó, en clave reveladora al fracaso que el sujeto experimenta en nuestras sociedades actuales, "los índices del fracaso pasado, interpelan al presente en condición de alegoría” (Alvear, 2000: 15). Arturo, y tras él, Arenas, reconstruyen una ciudad en donde abundan los objetos y las murallas, las puertas, los recovecos, las cavernas; una ciudad refugio que lo protegerá de aquella que en la realidad lo excluye.

\section{LA EVOLUCIÓN DEL TEMA DEL FRACASO EN LAS NARRATIVAS DE BOLAÑO Y ARENAS}

Latinoamérica es un lugar que alberga un sinfín de pluralidades relacionadas históricamente bajo una visión contradictoria que opone y homologa constantemente sus regiones ${ }^{12}$. En este espacio, procesos históricos similares han traído consecuencias radicalmente distintas para los sujetos que las padecen. Tal es el caso de las novelas estudiadas aquí. La irrupción de gobiernos militares durante la segunda mitad del siglo XX en gran parte de Latinoamérica motivó el surgimiento de una literatura comprometida con el develamiento y la denuncia de los abusos cometidos por los agentes reproductores de dichos órdenes (literatura del exilio por ejemplo). En este contexto, las tendencias (políticas, sociales, artísticas, etc.) relacionadas con ideologías de

${ }^{12}$ Podríamos definir, siguiendo a Coutinho, a América Latina como "una construcción múltiple, plural, móvil y variable y, por lo tanto, extremadamente problemática, creada para designar un conjunto de naciones, o mejor, pueblos que presentan diferencias fundamentales en todos los aspectos de su conformación -étnicos, culturales, sociales, económicos, políticos, históricos y geográficos- pero que al mismo tiempo presentan semejanzas significativas en todos estos mismos rasgos, especialmente cuando se los compara con los de otros pueblos" (2003: 42). 
izquierda (contra hegemónicas) se dedican a reivindicar constantemente la imagen de tales posturas, desde la periferia del poder, identificándose con un imaginario revolucionario, reivindicativo, popular e igualitario. El universo semántico que orbita, entonces, estas ideologías, acentúa sus rasgos positivos y encubre sus defectos como sistemas igualmente excluyentes. En este punto, las novelas estudiadas cobran vital relevancia ya que ponen en jaque este universo utópico al develar los defectos que dichos pensamientos albergan.

Bolaño, a diferencia de Arenas, nos enfrenta no solo con los defectos de la ideología reinante, sino más bien con el fracaso total y de todos a causa de nuestra incapacidad para comprender el universo cabalmente. Si bien Wieder personifica a un militar asesino y torturador, amparado por el régimen, al mismo tiempo alegoriza en él al sujeto que pretende estar por sobre las mundanas cuestiones éticas (la vanguardia) en una referencia directa a grupos artísticos contra hegemónicos que pretenden cuestionar el sistema reinante en la época. La postura, claramente más escéptica, apunta a develar las máscaras con las que estas ideologías ocultan su verdadero rostro (signado por el mal) denunciando, así, la naturaleza igual de excluyente y totalizadora de las distintas posiciones.

Este ejercicio evidencia un proceso evolutivo que, desde la óptica del fracaso como tema, tiende un hilo conductor que denuncia los abusos de ciertas tendencias, ahora en la novela de Arenas, diferenciando de forma binaria los actores sociales. Bajo esta clasificación, los personajes de Arenas deambulan en la dicotomía del bien y el mal. Los oprimidos (o los buenos) identificados con aquellos que la revolución excluyó (los encarcelados, entre los que cuenta Arturo) y los opresores (los malos), esos Otros que agreden y discriminan a los homosexuales, identificados aquí como los militares representantes de la revolución. La distopía, entonces, no se atribuye a la irrupción de dictaduras de derecha, como en el resto de Latinoamérica. Aquí, Arenas denuncia los sesgos de aquella Revolución Cubana que prometió ser la cuna de la libertad y en la cual él, en sus albores, también confió.

Para ejemplificar la contradicción que plantea la pérdida del ser, citamos un estudio de Pablo Catalán, que aborda la problemática de la pérdida del ser en la narrativa de Carlos Cerda:

Perder el ser. La primera pregunta es saber si el ser se puede perder. En el caso extremo del último límite, la muerte, es claro que se puede decir que se pierde el ser, se deja de ser. Pero como no se muere para uno mismo sino para los otros, el ser se substantiva y los que siguen en vida dicen que han perdido a un ser querido. El ser que se muere no pierde su ser sino que 
pierde su posibilidad de ser su ser y al perder esa posibilidad pierde tanto la posibilidad de ser como la posibilidad de perder: se hunde en la imposibilidad de ser. La segunda pregunta concierne al "estar". Baste con destacar dos posibilidades fundamentales de este verbo: por un lado significa una situación o estado que circunscribe una modalidad del ser; le da al ser una determinación que, aunque duradera, significa a la vez una limitación temporal posible [...] Por otro lado "estar" significa la modalidad del ser que se encuentra ahí: el ser-ahí en una situación determinada se expresa en la simplicidad y riqueza del "estar". Ahora bien, no se puede ser sin estar, pero se puede estar sin ser. El ejemplo extremo es por cierto el del cadáver: éste está pero su posibilidad de conciencia de ser ya no es posible (Catalán, 2003: 9).

La pérdida del ser, que desde su dimensión ontológica reconoce una imposibilidad es recogida, aquí, para denominar aquel estado que los Arturos de ambas estrellas, estudiados como alter egos de sus creadores, plasman en los mundos narrados. La trágica revelación de la 'descomunal estafa' (Arenas, 1984: 29) que significa para Arenas la revolución y la apocalíptica revelación del mal como eje transversal que se yuxtapone indiscriminadamente al 'bien' o a la 'verdad' (estos últimos en extremo relativos) en Bolaño, alimentan proyectos narrativos que configuran espacios signados por la decadencia, el deterioro, la destrucción, en donde reina el gobierno del mal. Estos espacios revisten circunstancias que se proyectan en el tiempo como procesos inacabables (e inacabados) que reúnen en sí el lapidario devenir del tiempo. Lo reconoce Arturo B ya al final de su periplo: "las estrellas cada vez más distantes" (Bolaño, 1996: 155), albergando en la escena la temporalidad, "se pasa de sustantivo a gerundio", dirá Claudio Gaete, "distanciándose, distanciándonos de la estrella" (Gaete, s/f). Para el Arturo de Reinaldo Arenas, esta visión es aún más devastadora, encerrado en la cárcel, en la plenitud de su vida, repite; "envejecer, envejecer, envejeciendo" (Arenas, 1984: 52), connotando en sus palabras la ralentización -pero nunca detención- del tiempo. La decepción frente a la realidad que transcurre ante sus ojos fractura la unidad que los sujetos se construían para enfrentar los designios del destino, resquebraja al ser, lo transforma en otro ente (¿un no ser?) que pierde, entre otras tantas cosas, la fe en los ideales, la esperanza en el futuro, algunos seres queridos. El sujeto se ancla en el pasado y al presente sólo llega un residuo de aquello que fue, un fragmento que permanece ausente, inserto en el pasado que se destruyó. Está, pero al mismo tiempo no está. La pérdida del ser. 


\section{REFERENCIAS}

Alvear, Idelber. (2000). Alegorías de la derrota: la ficción posdictatorial y el trabajo del duelo. Santiago de Chile: Cuarto Propio.

Arenas, Reinaldo. (1984). Arturo, la estrella más brillante. Barcelona: Montesinos.

Benjamin, Walter. (2008). El narrador. Introducción, traducción, notas e índices de Pablo Oyarzún. Santiago de Chile: Metales Pesados.

Bertot, Lillian. (s/f). Autencidad y opresión: La transformación Madre-Estado en el discurso subversivo de Reinaldo Arenas. Cuban American Review [en línea]. Disponible en http://www.cubanamericanreview.com/ TransformacionMadreEstado.pdf. Consulta: 23.09.2013.

Bolaño, Roberto. (1991). Monsieur Pain. Barcelona: Anagrama. . (1996). Estrella distante. Barcelona: Anagrama. . (1998). Los detectives salvajes. Barcelona: Anagrama.

Catalán, Pablo. (2003). Carlos Cerda: la pérdida del ser. Revista Mapocho, 54, 9-28 [en línea]. Disponible en http://www.dibam.cl/biblioteca_nacional/pdf/mapocho_54/Humanidades.pdf. Consulta: 23.09.2013.

Coutinho, Eduardo. (2003). Literatura comparada en América Latina. Ensayos. Cali: Programa Editorial.

Dés, Mihály. (1998). Entrevista a Bolaño. Lateral: Revista de Cultura, 40.

Dolezel, Lubomír. (1999). Una semántica para la temática: el caso del doble. En Estudios de poética y teorías de la ficción (pp. 159-174). Murcia: Universidad de Murcia.

Eliade, Mircea. (1963). Aspects du mythe. Gallimard: París.

Espinosa, Patricia. (2003). Territorios en fuga. Ensayos críticos sobre la obra de Roberto Bolaño. Santiago de Chile: Frasis Editores.

Foucault, Michel. (1996). El orden del discurso. Madrid: La Piqueta.

Gaete, Claudio. (s/f). Estrella distante y la metáfora del naufragio. Ensayo inédito.

Genette, Gerard. (1982). Palimpsestos. Selección de capítulos. París: Du Seuil.

Gnisci, Armando. (2002). Introducción a la literatura comparada. Barcelona: Crítica.

González, Daniuska. (2003). Roberto Bolaño: El resplandor de la sombra. La escritura del mal y la historia. Atenea, 488, 31-45.

Gordon, Rocío. (2008). La creación como culminación: forma y contenido en Arturo, la estrella más brillante de Reinaldo Arenas. Revista Iberoamericana Global, 1, 3, 201-217 [en línea]. Disponible en http://media.wix. 
com. Consulta: 23.09.2013.

Neustadt, Robert. (2001). CADA DÍA: La creación de un arte social. Santiago de Chile: Cuarto Propio.

Oliván. Lucía. (2004). La alegoría en El origen del drama barroco alemán de Walter Benjamin y en Las flores del mal de Baudelaire. A Parte Rei Revista de Filosofía, 36 [en línea]. Disponible en http://serbal.pntic.mec. es/ cmunoz11/olivan36.pdf. Consulta: 23.09.2013.

Ortega y Gasset, José. (1983). ¿Qué es filosofía? Madrid. Alianza Editorial.

Richard, Nelly. (2000). La insubordinación de los signos (cambio político, transformaciones culturales y poéticas de la crisis). Santiago de Chile: Cuarto Propio.

Sepúlveda, Magda. (2003). La narrativa policial como un género de la Modernidad: la pista de Bolaño. En Espinosa, Patricia (comp.) Territorios en fuga. Estudios críticos sobre la obra de Roberto Bolaño (pp. 103-115). Santiago de Chile: Frasis Editores.

Solotorevsky, Myrna. (2003). La relación mundo - escritura. Gaithersburg MD: Hispamérica.

Trocchi, Anna (2002). Temas y mitos literarios. En Armando Gnisci (comp.), Introducción a la literatura comparada (pp. 129-170). Barcelona: Crítica. 